\title{
Incidence, risk factors and prognostic factors of acute renal failure in patients admitted to an intensive care unit
}

\author{
S.E. Mataloun, F.R. Machado, \\ A.P.R. Senna, H.P. Guimarães \\ and J.L.G. Amaral
}

Disciplina de Anestesiologia, Dor e Terapia Intensiva, Universidade Federal de São Paulo, São Paulo, SP, Brasil
Correspondence

F.R. Machado

Disciplina de Anestesiologia,

Dor e Terapia Intensiva

Universidade Federal de São Paulo

R. Napoleão de Barros, 715, 4ํandar

04024-900 São Paulo, SP

Brasil

Fax: +55-11-5576-4069

E-mail: fmachado.dcir@epm.br

$\ldots \ldots \ldots \ldots \ldots \ldots \ldots$

Received June 15, 2005

Accepted June 5, 2006

\begin{abstract}
The objective of the present study was to assess the incidence, risk factors and outcome of patients who develop acute renal failure (ARF) in intensive care units. In this prospective observational study, 221 patients with a 48-h minimum stay, 18-year-old minimum age and absence of overt acute or chronic renal failure were included. Exclusion criteria were organ donors and renal transplantation patients. ARF was defined as a creatinine level above $1.5 \mathrm{mg} / \mathrm{dL}$. Statistics were performed using Pearsons' $\chi^{2}$ test, Student $t$-test, and Wilcoxon test. Multivariate analysis was run using all variables with $\mathrm{P}<0.1$ in the univariate analysis. ARF developed in $19.0 \%$ of the patients, with $76.19 \%$ resulting in death. Main risk factors (univariate analysis) were: higher intra-operative hydration and bleeding, higher death risk by APACHE II score, logist organ dysfunction system on the first day, mechanical ventilation, shock due to systemic inflammatory response syndrome (SIRS)/sepsis, noradrenaline use, and plasma creatinine and urea levels on admission. Heart rate on admission (OR $=1.023$ (1.002-1.044)), male gender $(\mathrm{OR}=4.275(1.340-13642))$, shock due to SIRS/sepsis (OR $=8.590(2.710-27.229))$, higher intra-operative hydration (OR $=1.002(1.000-1004)$ ), and plasma urea on admission $(\mathrm{OR}=1.012(0.980-1044))$ remained significant (multivariate analysis). The mortality risk factors (univariate analysis) were shock due to SIRS/sepsis, mechanical ventilation, blood stream infection, potassium and bicarbonate levels. Only potassium levels remained significant $(\mathrm{P}=0.037)$. In conclusion, ARF has a high incidence, morbidity and mortality when it occurs in intensive care unit. There is a very close association with hemodynamic status and multiple organ dysfunction.
\end{abstract}

\section{Introduction}

Despite the recent technological advances, there is still a high incidence of acute renal failure (ARF) in intensive care unit (ICU)
Key words

- Acute renal failure

- Risk factors

- Prognostic factors

- Intensive care unit

- Mortality leading to high mortality (1-6). ARF can be defined as a sudden and continuous decrease of glomerular function associated with azotemia, followed or not by decreased urinary output (7). It occurs mostly as part of a 
multiple organ dysfunction syndrome associated with the systemic inflammatory response syndrome (SIRS) and sepsis, but it can also occur as a separate event. Its incidence varies from 3 to $30 \%(4,8-11)$ with mortality ranging from 36 to $90 \%(1-4,11$, 12), depending on the type of ICU or type of patient assessed and the period during which the study is conducted. One of the factors that contribute to this high incidence and mortality is the greater morbidity of the patients currently admitted to ICU. Due to the better diagnostic and therapeutic resources available today, elderly patients and others with important co-morbidities, such as immunosuppression and chronic organ dysfunctions, undergo more aggressive treatments.

Several risk factors involved in the genesis of ARF have been analyzed in the medical literature. Obstetric bleeding and digestive hemorrhage, proposed by several investigators in earlier studies (5-8), have given way to consideration of other factors such as sepsis, shock, infections, use of contrast, and drug toxicity $(4,5,8,13,14)$. Other associated factors are congestive heart failure and acute myocardial infarction $(4,15,16)$, cirrhosis (4), chemotherapy (4), large burns (4), polytrauma, mostly associated with rhabdomyolysis, and surgery $(17,18)$, mainly, complex heart and vascular surgeries (6). Mechanical ventilation is a frequently reported factor (19), probably as a marker of multiple organ dysfunction syndrome.

Similarly, the risk factors for mortality are also multiple in patients with ARF. Studies have demonstrated the importance of age and male gender, the latter possibly due to preexistent vascular diseases $(1,3,4,6,10,13$, 20-23). The delay before ARF onset, Acute Physiology, Age and Chronic Health Evaluation II (APACHE II) score and length of stay in the ICU seem to be important, probably because they are markers of the severity of the patient's condition (24).

The objective of the present study was to evaluate the incidence of ARF among ICU patients with normal renal function on admission, as assessed by creatinine levels, and to analyze the risk and prognostic factors of ARF and its impact on the clinical course as well as the mortality of these patients.

\section{Patients and Methods}

This was a prospective observational study conducted in a general ICU of a tertiary care university hospital. From October 1, 1999 to September 30, 2000, 828 patients were admitted to the ICU and only 221 satisfied both the inclusion and exclusion criteria. They were assessed prospectively once they met all the inclusion criteria, such as 48 -h minimum stay, plasma creatinine levels of $1.5 \mathrm{mg} / \mathrm{dL}$ or lower, and minimum age of 18 years. Organ donors and renal transplant recipients were excluded.

The study was approved by the Ethics Committee of Hospital São Paulo.

On admission, demographic data were collected (gender and age), as well as category of admission (clinical, emergency surgical or elective surgical patients), cause of admission (infected or non-infected clinical patients and type of surgery), physiologic variables (heart rate, mean arterial pressure and central venous pressure), first 24-h stay water balance and APACHE II score with their respective death risk (25) and prior admission data (chronic diseases and previous length of hospital stay). Intraoperative data, such as surgery duration, surgical complications (bleeding, hypotension, hypoxemia, and acidemia), urinary output and hydration volume, as the total volume administered during surgery, were also recorded.

To quantify organ dysfunction, the logistic organ dysfunction system (LODS) score (26) was used on the first and seventh days. Laboratory evaluation was performed daily and included acid-base balance, sodium, potassium, urea, creatinine, hemogram, and 
coagulogram. Risk factors included use of radiocontrast media, nephrotoxic and vasoactive drugs before ARF onset, mechanical ventilation and occurrence of SIRS/sepsis, shock due to SIRS/sepsis, acute lung injury, and acute respiratory distress syndrome. $\mathrm{Pa}$ tients were followed until ICU discharge or death.

ARF was defined as a creatinine level above $1.5 \mathrm{mg} / \mathrm{dL}$. Patients who developed ARF were monitored for total water balance, duration of ARF episode, plasma bicarbonate levels, need for dialysis, and use of a diuretic in order to complete the evaluation of prognostic factors. Standard treatment of $\mathrm{ARF}$ and criteria to start renal replacement therapy were not protocolled or recorded. All clinical decisions were made by the attending physician.

Statistical analysis was performed using an SAS 6.12 database. Quantitative variables are reported as means \pm SD and qualitative variables as percentage. In the univariate analysis of risk factors we used the Student $t$-test or Wilcoxon test for the quantitative variables and the Pearsons' $\chi^{2}$ test for the qualitative ones. All variables with a $P$ value $<0.1$ in the univariate analysis were selected for multivariate analysis. The logistic regression forward method was used for multivariate analysis of the risk factor, and its results are reported as odds ratio (OR) and confidence interval. The logistic regression method could not be used to analyze the prognostic factors due to the instability of the model. Therefore, discriminating analysis was performed, with the level of significance set at $\mathrm{P}<0.05$.

\section{Results}

\section{Global data of the study population}

The demographic and overall features of the study population are shown in Table 1 . ARF occurred in 42 patients (19\%) of the study population.

\section{Risk factors for acute renal failure development}

There was no significant difference in mean age between patients with and without ARF (55.3 $\pm 18.4(20-85)$ years and $54.7 \pm$ 19.4 (18-94) years, respectively), with $\mathrm{P}=$ 0.873 . We observed a trend towards an increasing number of ARF cases among male patients compared to female patients (59.5 and $40.5 \%$, respectively, with $\mathrm{P}=0.053$ ). Although this difference was not statistically significant in univariate analysis, it was one of the significant variables in multi-

\begin{tabular}{lc}
$\begin{array}{l}\text { Table 1. General characteristics of the } 221 \text { pa- } \\
\text { tients studied. }\end{array}$ \\
\hline Age (years) \\
Gender \\
$\quad$ Female \\
$\quad$ Male \\
Chronic diseases \\
All \\
Hypertension & $119(53.8 \%)$ \\
Diabetes mellitus & $102(46.2 \%)$ \\
Coronary heart disease & $141(63.8 \%)$ \\
Category of admission & $79(35.7 \%)$ \\
Clinical & $31(14.0 \%)$ \\
Emergency surgery & $18(8.1 \%)$ \\
$\quad$ Elective surgery & \\
Type of surgery & $61(27.6 \%)$ \\
Neurosurgery & $62(28.1 \%)$ \\
Gastrosurgery & $98(44.3 \%)$ \\
$\quad$ Vascular surgery & \\
Surgical complications & \\
All & $45(20.4 \%)$ \\
Hypotension & $36(16.3 \%)$ \\
Bleeding & $22(9.9 \%)$ \\
APACHE II score & \\
Death risk & $50(22.6 \%)$ \\
1st day LODS score & $38(17.2 \%)$ \\
7th day LODS score & $29(13.1 \%)$ \\
Acute renal failure & $15.2 \pm 7.7$ \\
Mortality & $14.8 \pm 17.4$ \\
\hline & $5.3 \pm 3.0$ \\
& $6.9 \pm 4.7$ \\
& $19.0 \%$ \\
& $36.2 \%$
\end{tabular}

Data are reported as means \pm SD or as number of patients, with percent given in parentheses. All percentages refer to the total number of patients $(N=221)$. Only main categories are presented, and therefore the sum is not $100 \%$. ${ }^{\text {aA }}$ patient could have had more than one complication. APACHE II = Acute Physiology, Age and Chronic Health Evaluation II; LODS = logistic organ dysfunction system. 
variate analysis. Other significant differences between males and females could explain this finding. There was a higher number of surgical complications in males (28.4 and $17.6 \%$, respectively, with $\mathrm{P}=0.002$ ), including hypotension $(23.5$ vs $11.8 \%$, with $\mathrm{P}$ $=0.033)$ and bleeding (17.6 and 9.2\%, with $\mathrm{P}=0.065)$. Previous coronary heart disease

Table 2. Univariate analysis of risk factors for the development of acute renal failure (ARF).

\begin{tabular}{|c|c|c|c|}
\hline Characteristics & ARF patients & Non-ARF patients & $P$ \\
\hline Male gender & $25(59.5 \%)$ & $77(43.0 \%)$ & 0.053 \\
\hline Surgical complications & $15(46.5 \%)$ & $35(27.6 \%)$ & 0.035 \\
\hline Bleeding & $11(34.4 \%)$ & $18(14.2 \%)$ & 0.008 \\
\hline Hypotension & $12(37.5 \%)$ & $26(20.5 \%)$ & 0.04 \\
\hline SIRS/sepsis & $30(78.9 \%)$ & $75(41.9 \%)$ & 0.0001 \\
\hline Shock due to SIRS/sepsis & $21(50.0 \%)$ & $30(16.8 \%)$ & 0.0001 \\
\hline Use of noradrenaline & $15(39.5 \%)$ & $32(17.9 \%)$ & 0.003 \\
\hline Use of radiologic contrast & $4(9.5 \%)$ & $3(1.7 \%)$ & 0.026 \\
\hline Respiratory failure & $33(86.8 \%)$ & $99(55.3 \%)$ & 0.001 \\
\hline Previous length of stay (days) & $8.6 \pm 8.2$ & $6.9 \pm 10.1$ & 0.044 \\
\hline LODS score & $6.5 \pm 3.5$ & $5.02 \pm 2.9$ & 0.006 \\
\hline APACHE II score & $17.49 \pm 9.37$ & $14.59 \pm 7.14$ & 0.073 \\
\hline Death risk (\%) & $20.95 \pm 23.14$ & $13.19 \pm 15.24$ & 0.049 \\
\hline Urea on admission (mg/dL) & $41.36 \pm 18.98$ & $34.93 \pm 19.46$ & 0.048 \\
\hline Creatinine on admission (mg/dL) & $1.04 \pm 0.29$ & $0.88 \pm 0.26$ & 0.0007 \\
\hline Intraoperative hydration (mL/kg) & $124.23 \pm 117.83$ & $95.31 \pm 173.26$ & 0.0170 \\
\hline \multicolumn{4}{|c|}{ Chronic diseases } \\
\hline Hypertension & $15(35.7 \%)$ & $64(35.7 \%)$ & NS \\
\hline Diabetes mellitus & $7(16.7 \%)$ & $24(13.4 \%)$ & NS \\
\hline Coronary heart disease & $6(14.3 \%)$ & $12(6.7 \%)$ & NS \\
\hline COPD & $2(4.8 \%)$ & $11(6.1 \%)$ & NS \\
\hline \multicolumn{4}{|l|}{ Admission category } \\
\hline Clinical & $10(23.8 \%)$ & $51(28.5 \%)$ & NS \\
\hline Elective surgery & $21(50.0 \%)$ & $77(43.0 \%)$ & NS \\
\hline Emergency surgery & $11(26.2 \%)$ & $51(28.5 \%)$ & NS \\
\hline \multicolumn{4}{|l|}{ Nephrotoxic drugs } \\
\hline Aminoglycosides & $17(40.5 \%)$ & $58(32.4 \%)$ & NS \\
\hline Vancomycin & $14(33.3 \%)$ & $54(30.2 \%)$ & NS \\
\hline \multicolumn{4}{|l|}{ Vasoactive drugs } \\
\hline Dobutamine & $6(15.8 \%)$ & $12(6.7 \%)$ & NS \\
\hline Dopamine & $15(39.5 \%)$ & $14(25.1 \%)$ & NS \\
\hline \multicolumn{4}{|l|}{ Surgery characteristics } \\
\hline Length (min) & $325.5 \pm 183.3$ & $276.1 \pm 160.2$ & NS \\
\hline Urinary output (mL kg-1 $\mathrm{h}^{-1}$ ) & $4.5 \pm 6.2$ & $5.2 \pm 7.6$ & NS \\
\hline Age (years) & $55.3 \pm 18.4$ & $54.7 \pm 19.4$ & NS \\
\hline
\end{tabular}

Data were analyzed statistically by the Pearsons' $\chi^{2}$ test and the Student $t$-test. Data are reported as means $\pm S D$ or as number of patients, with percent given in parentheses. SIRS = systemic inflammatory response syndrome; LODS = logistic organ dysfunction system; APACHE II = Acute Physiology, Age and Chronic Health Physiology Evaluation II; COPD = chronic obstructive pulmonary disease. All variables with $\mathrm{P}<$ 0.1 were selected for multivariate analysis. NS $=$ not significant. and acute myocardial infarction were also more frequent in males than in females $(11.8$ vs $5.0 \%$, with $\mathrm{P}=0.068$ and 6.9 vs $0.8 \%$, with $\mathrm{P}=0.019$, respectively).

The mean hospital stay before ICU admission of ARF patients was longer than that of non-ARF patients $(8.6 \pm 8.2(0-31)$ days vs $6.9 \pm 10.1(0-55)$ days, with $\mathrm{P}=0.044)$. Surgical complications, namely bleeding and hypotension, were both more frequent among ARF patients (34.4 and 37.5\% in ARF patients $v s \quad 14.2$ and $20.5 \%$ in non-ARF patients, $\mathrm{P}=0.008$ and 0.04 , respectively). Intraoperative hydration was also related to ARF development $(\mathrm{P}=0.01$; Table 2$)$.

Organ dysfunction severity assessed by the LODS score on the first day of stay correlated with ARF development $(6.5 \pm 3.5$ - ARF patients vs $5.0 \pm 2.9$ - non-ARF patients, $\mathrm{P}=0.006$ ). However, when we used the APACHE II score this correlation was not very clear $(17.5 \pm 9.4$ - ARF patients vs $14.6 \pm 7.1$ - non-ARF patients, $\mathrm{P}=0.073$ ), although the death risk was significantly higher in the ARF population $(20.9 \pm 23.1$ ARF patients $v s 13.2 \pm 15.2$ - non-ARF patients, $\mathrm{P}=0.006$ ). Plasma creatinine and urea levels on admission were higher in the ARF population $(1.0 \pm 0.3(0.3-1.5)$ and $41.4 \pm 19.0(15.0-84.0) \mathrm{mg} / \mathrm{dL})$ compared to non-ARF patients $(0.9 \pm 0.3(0.2-1.5)$ and 34.9 $\pm 19.5(10.0-128.0) \mathrm{mg} / \mathrm{dL})$, with $\mathrm{P}=0.0007$ and 0.048 , respectively. SIRS/sepsis, shock due to SIRS/sepsis and respiratory failure requiring mechanical ventilation were associated with ARF development (Table 2).

Only the previous use of noradrenaline correlated with the development of ARF (39.5 and $17.9 \%$, ARF and non-ARF patients, respectively, with $\mathrm{P}=0.003$ ). Regarding nephrotoxic drugs, only the use of radiocontrast media was significantly more frequent among ARF patients (9.5\%) compared to the non-ARF ones $(1.7 \%)$, with $\mathrm{P}=$ 0.026 . The univariate analysis of risk factors is presented in Table 2 .

In multivariate analysis the variables that 
remained independently associated with ARF development are listed in Table 3. In the surgical subgroup analysis the same variables have been found (Table 3 ).

\section{Clinical outcome}

During the ICU stay the mortality of ARF patients $(76.2 \%)$ was significantly higher than that of non-ARF patients (27.0\%), with $\mathrm{P}=0.018$. There was also a significant increase of ICU length of stay in the first group $(16.1 \pm 13.3$ vs $12.7 \pm 14.9$ days, $\mathrm{P}=$ 0.018).

Patients developed ARF after a mean of $5.8 \pm 7.7$ (2-41) days of ICU stay. Creatinine levels remained high for a mean period of $7.8 \pm 8.4(2-33)$ days and mean peak levels were $3.3 \pm 1.8(1.6-9.1) \mathrm{mg} / \mathrm{dL}$. Among 42 patients with ARF, 41 (97.6\%) had at least one complication while in the group without ARF the rate reached $73.2 \%(\mathrm{P}=0.001)$. The most frequent complications can be seen in Table 4.

Organ dysfunction, when assessed by LODS score on the seventh day, was more severe in patients with ARF (10.8 \pm 4.8 (4-22) vs $6.1 \pm 4.3(0-17), \mathrm{P}=0.0001)$. The accumulated water balance was higher in patients with $\operatorname{ARF}(78.6 \%)$ than in those without it (54.2\%), with $\mathrm{P}=0.004$. Only 10 patients $(23.8 \%)$ needed renal replacement therapy and all of these received hemodialysis.

\section{Analysis of risk factors for mortality in acute renal failure patients}

Univariate analysis showed that the presence of shock due to SIRS/sepsis, respiratory failure requiring mechanical ventilation, plasma bicarbonate levels, and potassium levels correlated with mortality (Table 5). The variables that did not correlate with mortality are also shown in Table 5. In the discriminating analysis, only potassium levels remained as a risk factor for mortality, with $\mathrm{P}=0.037$.

\section{Discussion}

The definition of ARF is not uniform in the medical literature. Most studies, even the latest ones, have used biochemical criteria based on plasma creatinine levels, whereas others were based on the need for dialysis $(1-4,6,7)$. Kidney tomography or biopsy has also been used (1). This heterogeneity of criteria makes the comparison among studies extremely difficult (27). The criterion

Table 3. Risk factors associated with the development of acute renal failure (ARF) identified by multivariate analysis.

\begin{tabular}{lll}
\hline Characteristics & OR & Cl (95\%) \\
\hline Total population $(\mathrm{N}=221)$ & & \\
$\quad$ Heart rate on admission & 1.023 & $1.002-1.044$ \\
Male gender & 4.275 & $1.340-13.642$ \\
Shock due to SIRS/sepsis & 8.590 & $2.710-27.229$ \\
Intraoperative hydration & 1.002 & $1.000-1.004^{\mathrm{NS}}$ \\
$\quad$ Urea on admission & 1.012 & $0.980-1.044$ \\
Surgical patients $(\mathrm{N}=160)$ & & \\
Heart rate on admission & 1.025 & $1.004-1.047$ \\
Male gender & 3.943 & $1.235-12.590$ \\
Shock due to SIRS/sepsis & 9.421 & $2.912-30.480$ \\
Intra-operative hydration & 1.002 & $1.000-1.004 \mathrm{NS}$ \\
$\quad$ Urea on admission & 1.011 & $0.979-1.044 \mathrm{NS}$ \\
\hline
\end{tabular}

Multiple regression, $\mathrm{OR}=$ odds ratio; $\mathrm{Cl}=$ confidence interval $(95 \%) ; \mathrm{SIRS}=$ systemic inflammatory response syndrome.

NSNot significant.

Table 4. Incidence of complications during the stay in the intensive care unit.

\begin{tabular}{lccc}
\hline Complications & ARF patients & Non-ARF patients & P \\
\hline Respiratory failure & $38(85.7 \%)$ & $104(51.1 \%)$ & 0.0001 \\
ALI & $14(33.3 \%)$ & $43(24.0 \%)$ & NS \\
ARDS & $9(21.4 \%)$ & $12(6.7 \%)$ & 0.007 \\
Pulmonary embolism & $2(4.8 \%)$ & $0(0.0 \%)$ & 0.035 \\
SIRS/sepsis & $35(83.3 \%)$ & $79(44.1 \%)$ & 0.0001 \\
Shock due to SIRS/sepsis & $28(68.3 \%)$ & $30(16.8 \%)$ & 0.0001 \\
Infectious complications & $18(42.9 \%)$ & $50(27.9 \%)$ & NS \\
Blood stream infection & $10(23.8 \%)$ & $20(11.2 \%)$ & 0.031 \\
Pneumonia & $16(38.1 \%)$ & $49(27.4 \%)$ & NS \\
Urinary tract infection & $3(7.1 \%)$ & $5(2.8 \%)$ & NS \\
\hline
\end{tabular}

Data are reported as number of patients, with percent given in parentheses. Total number of patients $=221$. Pearsons' $\chi^{2}$ test. $A R F=$ acute renal failure; $A L I=$ acute lung injury; ARDS = acute respiratory distress syndrome; SIRS = systemic inflammatory response syndrome; NS = not significant. 
adopted here was based on a rather wide definition, with high sensitivity, in order to detect as large a number of patients as possible. Based on this definition, we found an incidence of $19.0 \%$, which agrees with studies in similar populations $(3,8,13,15,17)$. Within the inclusion criteria, patients with previous renal dysfunction were not evaluated in order to obtain the real incidence of ARF inside the ICU. Thus, we tried to disregard all patients who presented worsening of chronic renal failure. Therefore, the real

\begin{tabular}{|c|c|c|c|}
\hline Characteristic & $\begin{array}{l}\text { Survivors } \\
(N=10)\end{array}$ & $\begin{array}{l}\text { Non-survivors } \\
\quad(\mathrm{N}=32)\end{array}$ & $P$ \\
\hline Shock due to SIRS/sepsis & $1(11.1 \%)$ & $27(84.4 \%)$ & 0.0001 \\
\hline Respiratory failure & $6(60.0 \%)$ & $30(93.7 \%)$ & 0.021 \\
\hline Blood stream infection & $0(0.0 \%)$ & $10(31.3 \%)$ & 0.084 \\
\hline Use of noradrenaline & $1(10.0 \%)$ & $14(43.7 \%)$ & 0.068 \\
\hline Plasma bicarbonate levels (mEq/L) & $18.4 \pm 3.8$ & $15.3 \pm 4.1$ & 0.037 \\
\hline Plasma potassium levels (mEq/L) & $5.0 \pm 1.0$ & $6.0 \pm 0.8$ & 0.013 \\
\hline Male gender & $5(50.0 \%)$ & $20(62.5 \%)$ & NS \\
\hline Chronic diseases & $7(70.0 \%)$ & $21(65.6 \%)$ & NS \\
\hline Surgical complications & $4(44.4 \%)$ & $11(47.8 \%)$ & NS \\
\hline Clinical complications & $9(90.0 \%)$ & $32(100.0 \%)$ & NS \\
\hline Infectious complications & $2(11.1 \%)$ & $16(88.9 \%)$ & NS \\
\hline SIRS/sepsis & $7(20.0 \%)$ & $28(80.0 \%)$ & NS \\
\hline ARDS & $1(10.0 \%)$ & $8(25.0 \%)$ & NS \\
\hline Use of dobutamine & $2(20.0 \%)$ & $5(15.6 \%)$ & NS \\
\hline Use of dopamine & $3(30.0 \%)$ & $17(53.1 \%)$ & NS \\
\hline Need for hemodyalisis & $0(0.0 \%)$ & $9(28.1 \%)$ & NS \\
\hline Age (years) & $58.80 \pm 19.57$ & $54.16 \pm 18.17$ & NS \\
\hline Urea levels at admission (mg/dL) & $42.23 \pm 19.43$ & $38.14 \pm 18.22$ & NS \\
\hline Lower $\mathrm{PaO}_{2} / \mathrm{FiO}_{2}$ rate & $351.63 \pm 264.41$ & $310.50 \pm 127.95$ & NS \\
\hline Creatinine levels at admission $(\mathrm{mg} / \mathrm{dL})$ & $1.04 \pm 0.25$ & $1.04 \pm 0.43$ & NS \\
\hline ICU stay (days) & $19.50 \pm 18.42$ & $15.09 \pm 11.51$ & NS \\
\hline Hospital stay before ICU (days) & $10.88 \pm 10.47$ & $8.03 \pm 7.70$ & NS \\
\hline APACHE II score & $17.94 \pm 9.23$ & $15.75 \pm 10.33$ & NS \\
\hline 1st day LODS score & $6.60 \pm 3.95$ & $6.44 \pm 3.37$ & NS \\
\hline 7th day LODS score & $8.16 \pm 2.40$ & $11.80 \pm 5.13$ & NS \\
\hline Duration of abnormal creatinine (days) & $7.80 \pm 9.86$ & $7.78 \pm 8.07$ & NS \\
\hline Levels of creatinine $(\mathrm{mg} / \mathrm{dL})$ & $3.03 \pm 2.10$ & $3.39 \pm 1.72$ & NS \\
\hline Urine output post-ARF $(\mathrm{mL} / \mathrm{kg})$ & $235.77 \pm 302.63$ & $215.98 \pm 255.18$ & NS \\
\hline Diuretic use (number of vials) & $4.00 \pm 4.24$ & $13.71 \pm 22.84$ & NS \\
\hline
\end{tabular}

Data are reported as means \pm SD or as number of patients, with percent given in parentheses. SIRS = systemic inflammatory response syndrome; ARDS = acute respiratory distress syndrome; $\mathrm{PaO}_{2} / \mathrm{FiO}_{2}=$ arterial $\mathrm{O}_{2}$ partial pressure/inspired pressure of $\mathrm{O}_{2} ; \mathrm{ICU}=$ intensive care unit; APACHE II = Acute Physiology, Age and Chronic Health Physiology Evaluation II; LODS = logistic organ dysfunction system; ARF = acute renal failure. All variables with $\mathrm{P}<0.1$ were selected for multivariate analysis. NS $=$ not significant. magnitude of the problem may have been underestimated.

The unit where the study was conducted is predominantly surgical, with a consequent basically very complicated postoperative population, since the inclusion only of patients with more than $48 \mathrm{~h}$ of ICU admission excluded the majority of uncomplicated elective surgical patients. The mean hospital stay prior to admission was long, with a high frequency of associated co-morbidities. These overlapping factors characterized a high-risk population, explaining the high mortality of the ARF patients studied. There is a wide range of reported mortality rates and this could be secondary to a wide variation in patient characteristics and practice patterns across institutions.

However, the mean APACHE II score and its respective death risk were relatively low compared to other studies. There was a difference between predicted and real mortality suggesting that this index is not appropriate for ARF assessment. This finding has been reported previously $(28,29)$. On the other hand, LODS score on the first ICU admission day has proved to be very suitable for mortality assessment. It is possible that the first $24 \mathrm{~h}$ of admission do not define so clearly the prognosis in the population with ARF as the severity of organ dysfunction of these patients would do.

Our results show that men were more affected than women, presenting a 4-fold higher risk ( $\mathrm{OR}=4.275)$. This was an interesting finding since male gender and shock were the variables with strongest association with ARF in multivariate analysis. This finding has also been reported by others (13). The greater number of surgical complications, such as hypotension and bleeding as well as the presence of previous coronary heart disease and acute myocardial infarction may have contributed to this finding. Differences related to gender are common in the population of critically ill patients. For instance, it has been shown that sepsis is 
more frequent among men (30) and renal failure is part of the organ dysfunction context in sepsis. It is also possible that still unknown genetic aspects may have influenced the incidence of ARF in the male population.

Few studies have assessed the impact of surgical complications on ARF development, in spite of their potential as risk factors (3133). The mean volume replacement during the intraoperative period among the patients that developed ARF was higher than in the patients that did not, and this factor remained as an independent risk factor in multivariate analysis, although with a low OR. Higher intraoperative hydration can be a marker of disease severity, since more severely ill patients need more fluid during surgery. On the other hand, giving fluids to the surgical patient can by itself increase morbidity. Interstitial edema is a concern in this population as it predisposes to suture dehiscence, with wounds being less prone to healing. Our study was not designed to address this question, and therefore only an association can be considered with no causality assessment.

Although it did not remain in the multivariate analysis, the small difference in creatinine levels on admission in these two populations was highly significant $(\mathrm{P}=0.0007)$. Hypotension or hypovolemia could have contributed. This fact may have clinical implications since a surgical patient admitted to the ICU with slightly elevated creatinine levels must be considered and treated as a patient at risk to develop ARF.

Like other investigators $(5,6,8)$, we found shock due to SIRS/sepsis as a risk factor associated with ARF development both in the group as a whole and in the subgroup of surgical patients. Although resulting hypotension is the most quoted factor, not all pathophysiologic mechanisms of sepsis are clear, and therefore the relationship with ARF development is still a matter of discussion $(34,35)$. The absence of correlation with the use of nephrotoxic drugs may suggest that pre-renal causes are the leading pathophysiological phenomena. These results strengthen the fundamental role of hemodynamic instability in the onset of ARF within the organ dysfunction context of a patient with sepsis or with an inflammatory response secondary to other aggression agents.

Among the prognostic factors, four were associated with a worse outcome of patients with ARF: shock due to SIRS/sepsis, respiratory failure with mechanical ventilation, plasma bicarbonate levels, and maximum plasma potassium levels. The only variable that remained significant in the multivariate analysis was the maximum plasma potassium level. This suggests that ARF seriousness assessed by this variable is a determinant of the prognosis of these patients. However, this analysis may have been confounded by the small number of patients in each subgroup, which prevented logistic regression analysis.

The present study had some limitations. Many patients with normal creatinine levels during ICU stay could have been considered to have ARF, if other criteria such as creatinine clearance had been used. Thus, the real incidence of ARF may have been underreported here. There is also the same problem regarding our inclusion criteria since patients already with ARF but with normal creatinine levels on admission could have been included. It is well known that ARF can be present in patients with normal creatinine levels, mostly middle-aged or elderly patients. Thus, strictly speaking, our incidence of ARF cannot be considered as the true incidence in patients with previous normal renal function, since several patients in our sample could have, in fact, mild or moderate chronic renal failure if estimated by creatinine clearance. Nonetheless, there is no consensus in the literature regarding ARF definition and all other criteria, even calculated or measured creatinine clearance, have their own limitations.

Another limitation of our study is the low 
OR observed during multivariate analysis. Despite a significant $\mathrm{P}$ value, the clinical significance of these results is questionable. Moreover, the confidence intervals frequently involved the unit (1.0), such as intraoperative hydration, urea levels on admission and even heart rate on admission (1.0021.044), which could compromise the strength of our results. It is possible that our small sample size (221) is responsible for these low intervals. For this reason, our results should be interpreted with caution.

There is a high incidence of ARF in ICU patients who do not present it on admission, with a high mortality rate. Risk and prognostic factors are primarily related to hemodynamic status. The global knowledge of the factors involved in the onset and prognosis of ARF is of fundamental importance regarding the management of critically ill patients. The high mortality associated with this organ dysfunction causes it to be somewhat more feared than other dysfunctions, such as acute respiratory distress syndrome, disseminated intravascular coagulation or even septic shock itself.

\section{References}

1. Akposso K, Hertig A, Couprie R, Flahaut A, Alberti C, Karras GA, et al. Acute renal failure in patients over 80 years old: 25 -years' experience. Intensive Care Med 2000; 26: 400-406.

2. Cole L, Bellomo R, Silvester W, Reeves JH. A prospective, multicenter study of the epidemiology, management, and outcome of severe acute renal failure in a "closed" ICU system. Am J Respir Crit Care Med 2000; 162: 191-196.

3. Guerin C, Girard R, Selli JM, Perdrix JP, Ayzac L. Initial versus delayed acute renal failure in the intensive care unit. A multicenter prospective epidemiological study. Rhone-Alpes Area Study Group on Acute Renal Failure. Am J Respir Crit Care Med 2000; 161: 872879.

4. de MA, Vincent JL, Suter PM, Moreno R, Dearden NM, Antonelli M, et al. Acute renal failure in the ICU: risk factors and outcome evaluated by the SOFA score. Intensive Care Med 2000; 26: 915-921.

5. Routh GS, Briggs JD, Mone JG, Ledingham IM. Survival from acute renal failure with and without multiple organ dysfunction. Postgrad Med J 1980; 56: 244-247.

6. Sural S, Sharma RK, Singhal MK, Kher V, Gupta A, Arora P, et al. Acute renal failure in an intensive care unit in India - prognostic factors and outcome. J Nephrol 1999; 12: 390-394.

7. Nissenson AR. Acute renal failure: definition and pathogenesis. Kidney Int 1998; 66 (Suppl): S7-S10.

8. Kraman S, Khan F, Patel S, Seriff N. Renal failure in the respiratory intensive care unit. Crit Care Med 1979; 7: 263-266.

9. Menashe PI, Ross AS, Gottlieb JE. Acquired renal insufficiency in critically ill patients. Crit Care Med 1988; 16: 1106-1109.

10. Hoste EA, Lameire NH, Vanholder RC, Benoit DD, Decruyenaere $\mathrm{JM}$, Colardyn FA. Acute renal failure in patients with sepsis in a surgical ICU: predictive factors, incidence, comorbidity, and outcome. J Am Soc Nephrol 2003; 14: 1022-1030.

11. Bernieh B, Al Hakim M, Boobes Y, Siemkovics E, El Jack H. Outcome and predictive factors of acute renal failure in the intensive care unit. Transplant Proc 2004; 36: 1784-1787.

12. Mehta RL, Pascual MT, Soroko S, Savage BR, Himmelfarb J, Ikizler $\mathrm{TA}$, et al. Spectrum of acute renal failure in the intensive care unit: the PICARD experience. Kidney Int 2004; 66: 1613-1621.
13. Brivet FG, Kleinknecht $D J$, Loirat $P$, Landais $P J$. Acute renal failure in intensive care units - causes, outcome, and prognostic factors of hospital mortality; a prospective, multicenter study. French Study Group on Acute Renal Failure. Crit Care Med 1996; 24: 192-198.

14. Yegenaga I, Hoste E, Van Biesem W, Vanholder R, Benoit D, Kantarci G, et al. Clinical characteristics of patients developing ARF due to sepsis/systemic inflammatory response syndrome: results of a prospective study. Am J Kidney Dis 2004; 43: 817-824.

15. Groeneveld AB, Tran DD, van der Meulen J, Nauta JJ, Thijs LG. Acute renal failure in the medical intensive care unit: predisposing, complicating factors and outcome. Nephron 1991; 59: 602-610.

16. Behrend T, Miller SB. Acute renal failure in the cardiac care unit: etiologies, outcomes, and prognostic factors. Kidney Int 1999; 56 : 238-243.

17. Vivino G, Antonelli M, Moro ML, Cottini F, Conti G, Bufi M, et al. Risk factors for acute renal failure in trauma patients. Intensive Care Med 1998; 24: 808-814.

18. Morris JA Jr, Mucha P Jr, Ross SE, Moore BF, Hoyt DB, Gentilello L, et al. Acute posttraumatic renal failure: a multicenter perspective. $J$ Trauma 1991; 31: 1584-1590.

19. Noble JS, MacKirdy FN, Donaldson SI, Howie JC. Renal and respiratory failure in Scottish ICUs. Anaesthesia 2001; 56: 124-129.

20. Liano F, Junco E, Pascual J, Madero R, Verde E. The spectrum of acute renal failure in the intensive care unit compared with that seen in other settings. The Madrid Acute Renal Failure Study Group. Kidney Int Suppl 1998; 66: S16-S24.

21. Wardle EN. Acute renal failure and multiorgan failure. Nephron 1994; 66: 380-385.

22. Carbonell N, Blasco M, Ferreres J, Blanquer J, Garcia-Ramon R, Mesejo A, et al. Sepsis and SOFA score: related outcome for critically ill renal patients. Clin Nephrol 2004; 62: 185-192.

23. Carbonell N, Blasco M, Sanjuan R, Garcia-Ramon R, Blanquer J, Carrasco AM. Acute renal failure in critically ill patients. A prospective epidemiological study. Nefrologia 2004; 24: 47-53.

24. Schroeder TH, Hansen M, Dinkelaker K, Krueger WA, Nohe B, Fretschner R, et al. Influence of underlying disease on the outcome of critically ill patients with acute renal failure. Eur $J$ Anaesthesiol 
2004; 21: 848-853.

25. Knaus WA, Draper EA, Wagner DP, Zimmerman JE. APACHE II: a severity of disease classification system. Crit Care Med 1985; 13: 818-829.

26. Le Gall JR, Klar J, Lemeshow S, Saulnier F, Alberti C, Artigas A, et al. The logistic organ dysfunction system. A new way to assess organ dysfunction in the intensive care unit. ICU Scoring Group. JAMA 1996; 276: 802-810.

27. Bellomo R, Kellum J, Ronco C. Acute renal failure: time for consensus. Intensive Care Med 2001; 27: 1685-1688.

28. Batista PB, Cendorogolo NM, dos Santos OF, Carvalho Bacelar AC, Batista CG, dos Santos ES. Evaluation of prognostic indexes in critical acute renal failure patients. Ren Fail 2004; 26: 545-552.

29. Angus DC, Linde-Zwirble WT, Lidicker J, Clermont G, Carcillo J, Pinsky MR. Epidemiology of severe sepsis in the United States: analysis of incidence, outcome, and associated costs of care. Crit Care Med 2001; 29: 1303-1310.

30. d'Avila DO, Cendoroglo NM, dos Santos OF, Schor N, de Figueiredo $\mathrm{CE}$. Acute renal failure needing dialysis in the intensive care unit and prognostic scores. Ren Fail 2004; 26: 59-68.

31. Sanchez EQ, Gonwa TA, Levy MF, Goldstein RM, Mai ML, Hays $\mathrm{SR}$, et al. Preoperative and perioperative predictors of the need for renal replacement therapy after orthotopic liver transplantation. Transplantation 2004; 78: 1048-1054.

32. Regner KR, Connolly HM, Schaff HV, Albright RC. Acute renal failure after cardiac surgery for carcinoid heart disease: incidence, risk factors, and prognosis. Am J Kidney Dis 2005; 45: 826-832.

33. Bove T, Calabro MG, Landoni G, Aletti G, Marino G, Crescenzi G, et al. The incidence and risk of acute renal failure after cardiac surgery. $J$ Cardiothorac Vasc Anesth 2004; 18: 442-445.

34. Van Biesen W, Yegenaga I, Vanholder R, Verbeke F, Hoste E, Colardyn F, et al. Relationship between fluid status and its management on acute renal failure (ARF) in intensive care unit (ICU) patients with sepsis: a prospective analysis. J Nephrol 2005; 18: 5460.

35. Schrier RW, Wang W, Poole B, Mitra A. Acute renal failure: definitions, diagnosis, pathogenesis, and therapy. J Clin Invest 2004; 114: 5-14. 